\title{
Estudos culturais e epistemologias feministas: contribuições para pesquisas em comunicação no desenvolvimento regional
}

\author{
Ângela Cristina Trevisan Felippi' \\ Fernanda Nunes da Silveira ${ }^{2}$
}

\begin{abstract}
Resumo:
O artigo apresenta contribuições a partir da associação entre a teoria dos Estudos Culturais e as Epistemologias Feministas para pesquisas sobre a Comunicação no Desenvolvimento Regional. É sabido que os Estudos Culturais têm tradição nos estudos feministas; e as Epistemologias Feministas, por sua vez, oferecem uma perspectiva de investigação que considera as mulheres, suas práticas e realidades para a construção do conhecimento. $\mathrm{O}$ artigo se vale de revisão teórica, abordando as duas teorias e identificando pontos de aderência entre ambas. Infere que a aproximação das duas amplia as possibilidades para o estudo dos fenômenos comunicacionais tornados objetos de pesquisa na área do Desenvolvimento Regional, espaço acadêmico que tem se aberto para estudos de gênero.
\end{abstract}

Palavras-chaves: Estudos Culturais. Epistemologias Feministas. Comunicação.

\begin{abstract}
:
The article presents contributions from the association between the theory of Cultural Studies and Feminist Epistemologies for researches on Communication in Regional Development. It is known that Cultural Studies have a tradition in feminist studies; and Feminist Epistemologies, in turn, offer an investigative perspective that considers women, their practices and realities for the construction of knowledge. The article uses a theoretical review, addressing both theories and identifying points of adherence between them. It infers that the approximation of the two expands the possibilities for the study of communicational phenomena that have become objects of research in the area of Regional Development, academic space that has been open to gender studies.
\end{abstract}

Keywords: Cultural Studies, Feminist Epistemologies, Communication

\footnotetext{
1 Doutora em Comunicação Social pela Pontifícia Universidade Católica do Rio Grande do Sul (2006), mestre em Comunicação e Informação pela Universidade Federal do Rio Grande do Sul (2000) e graduada em Comunicação Social - Jornalismo pela Universidade Federal de Santa Maria (1990) e em História pela Faculdade de Filosofia Ciências e Letras Imaculada Conceição (1991). Pós-doutorado em Comunicación - Recepción y Cultura, da Universidad Católica del Uruguay (2019). angelafe@unisc.br

2 Graduada em Comunicação Social, na habilitação de Jornalismo, na Universidade de Santa Cruz do Sul (Unisc) em 2020. Mestranda em Desenvolvimento Regional na Unisc desde 2021 (Bolsista CAPES Modalidade 2 - Mestrado). fernandandsilveira@gmail.com
} 


\section{VOZES $_{\text {\&IÁLORO }}^{\mid}$}

Itajaí, V. 20, n.02, jun-dez 2021

\section{Introdução}

Esse artigo propõe pensar como os Estudos Culturais e as Epistemologias Feministas podem ser articulados em pesquisas na área de Comunicação e Desenvolvimento. Os Estudos Culturais analisam as diversas práticas sociais e culturais do cotidiano e as Epistemologias Feministas apresentam um olhar para as realidades das mulheres e para a sua construção de conhecimentos.

Uma conceituação possível de Comunicação e Desenvolvimento pode ser como subárea que estuda as relações sociais que são mediadas pela linguagem e pela cultura, as quais tenham objetivos relacionados ao desenvolvimento (FELIPPI, 2020). A articulação entre os Estudos Culturais e as Epistemologias Feministas dentro dessa subárea apresenta possibilidades para investigações interdisciplinares que envolvam os grupos sociais marginalizados e as relações desiguais de poder nos diferentes contextos culturais e territórios.

Após a introdução, tratamos, na primeira seção, sobre os Estudos Culturais e sua concepção de cultura, considerando as contribuições do feminismo dentro desse campo. $\mathrm{Na}$ segunda seção, abordamos as Epistemologias Feministas, suas características e suas críticas ao modelo dominante de ciência. Na terceira seção, estabelecemos algumas articulações e relações entre os Estudos Culturais e as Epistemologias Feministas, indicando possíveis contribuições para pesquisas envolvendo a Comunicação no campo do Desenvolvimento Regional. Por fim, apresentamos as considerações finais e as referências consultadas.

\section{Os estudos culturais e sua visão de cultura}

O campo dos Estudos Culturais surgiu no Centro de Estudos Culturais Contemporâneos criado pelos pesquisadores Richard Hoggart, Raymond Williams e Edward Palmer Thompson em 1964, na Universidade de Birmingham, na Inglaterra. Eles se caracterizam por terem uma abordagem interdisciplinar e por apresentarem uma maneira própria de pensar e relacionar cultura e sociedade. Esse campo se consolidou e se popularizou com os trabalhos do jamaicano Stuart Hall, que dirigiu o centro de 1969 a 1979. Com o passar do tempo, os estudos chegaram aos Estados Unidos, Austrália, Canadá, países da África e da América Latina, entre outros lugares. Em cada um deles, as pesquisas se desenvolveram de acordo com o contexto cultural do país, visto que não existe um conjunto de conceitos fixos que se aplicam a todas as regiões do mundo.

$\mathrm{Na}$ América Latina, os Estudos Culturais se desenvolveram com autores como Jesús-Martín Barbero, Nestor Garcia Canclini e Renato Ortiz. Nos American Latin Cultural Studies (Estudos Culturais Latino-Americanos), esses autores buscaram pensar e 


\section{VOZES $_{\text {\&IÁLORO }}^{\mid}$}

Itajaí, V. 20, n.02, jun-dez 2021

construir seus próprios quadros conceituais (FELIPPI; BRANDT, 2016) a partir de seus próprios contextos culturais e territórios.

Os Estudos Culturais buscam investigar os mais diversos elementos que perfazem as culturas existentes no mundo. Propõem uma abordagem interdisciplinar dos processos culturais como interdependentes e não como fenômenos isolados (ESCOSTEGUY, 2010). Esse modo de abordar os fenômenos sociais se deve a uma concepção de cultura que vai além da descrição dos costumes de um grupo ou sociedade e da ideia de hierarquia entre culturas, pois envolve as diferentes manifestações culturais e práticas sociais.

A cultura é comum a todos, está em todas as formas de pensar e toda sociedade humana tem seus próprios propósitos e significados, que se manifestam nas instituições, nas artes e no conhecimento (WILLIAMS, 1989). Contudo, o autor esclarece que ela não é igual para todos. A cultura só existe com o sujeito e suas ações em determinada realidade e os seres humanos participam da construção e das modificações da sua cultura.

A cultura penetra e está em cada canto da vida social contemporânea, espalhandose por ambientes secundários, mediando tudo (HALL, 1997) e é, portanto, um elemento central da sociedade. Ela perpassa todas as práticas sociais e organiza o interrelacionamento das mesmas (HALL, 2003a), moldando e orientando as práticas sociais das pessoas, influenciando sua conduta na sociedade.

Os Estudos Culturais promovem o alargamento do conceito de cultura, incluindo práticas e sentidos do cotidiano da vida social e propiciando que todas as expressões culturais sejam vistas, considerando o contexto social das instituições, relações de poder e história (ESCOSTEGUY, 2010). Nessas relações de poder, há constantemente movimentos de conflito entre os interesses, os valores e os modos de pensar dos diferentes grupos sociais. Nesse sentido, os Estudos Culturais oferecem recursos para ação social de resistência ou mudança, porque teorizam a complexidade e as contradições das formas de cultura e de comunicação na vida das pessoas e se preocupam em mostrar como elas servem de instrumento de dominação (CUNHA, 2010) nas diversas esferas da vida social.

Cultura e desenvolvimento regional são termos profundamente relacionados e a cidade, a região e o estado-nação são constituídos a partir de expressões e condições culturais, pois a cultura envolve práticas de significação e é permeada por relações de poder (FELIPPI; BRANDT, 2016). Ao realizar estudos sobre as culturas e as práticas culturais, as relações de poder existentes na sociedade são analisadas e podemos perceber seus impactos nas dimensões do desenvolvimento regional.

Em relação às práticas comunicacionais, como a jornalística, elas são entendidas como práticas sociais que são influenciadas pelas relações de poder e pelo contexto cultural. No campo do Desenvolvimento Regional, a discussão sobre comunicação e cultura vai além da perspectiva da dimensão cultural e sua função orgânica, pois a comunicação está presente na relação entre cultura e espaço (FELIPPI, BRANDT, 2016), 


\section{VOZES SEIÁLOGO}

Itajaí, V. 20, n.02, jun-dez 2021

mediando tudo. Isso porque os acontecimentos cotidianos são permeados pela comunicação e fazem parte da cultura, influenciando e sendo influenciados por ela.

O jornalismo se apresenta como produto e produtor da cultura e, inclusive, pode ser considerado como o quarto poder, pois pode exercer influências sobre a sociedade. Com os Estudos Culturais, a comunicação e a mídia podem ser analisadas nas suas relações de poder e com a ideologia, incluindo as práticas de indivíduos e grupos que não estão representados no cenário midiático hegemônico.

\section{As contribuições do feminismo para os Estudos Culturais}

Para Hall (2003b), o feminismo foi uma das rupturas teóricas no trabalho do Centro de Estudos Culturais Contemporâneos. Esse movimento reorganizou o campo de diversas maneiras, tais como: a proposição da questão do pessoal como político e a mudança do objeto de estudo; a expansão da noção de poder que, até então, era trabalhada somente no âmbito da esfera pública; a centralidade das questões de gênero e sexualidade para a compreensão do próprio poder; a abertura para questões a respeito do subjetivo e do sujeito; a reabertura da fronteira entre a teoria social e a teoria do Inconsciente - a psicanálise (HALL, 2003b).

Em 1974, foi formado o Grupo de Estudos da Mulher ${ }^{3}$ no Centro de Estudos Culturais Contemporâneos com trabalhos sobre as mídias e os públicos femininos, a literatura produzida por escritoras mulheres e a problematização do papel da mulher na esfera doméstica e da família. A maior parte dos trabalhos do grupo foi publicada no livro Women Take Issue (1978) ${ }^{4}$. Essa obra deu visibilidade à atividade intelectual em torno de um projeto feminista, demonstrando as diferenças e fragilidades existentes no grupo, e demarcou uma área de atuação específica no campo acadêmico, delineando novos objetos de estudo (ESCOSTEGUY, 1998).

Na década de 1970, as pesquisas se basearam em uma concepção universalizante e unificadora das mulheres. Todas elas sofrem com o patriarcado e, portanto, vivem experiências em comum (ESCOSTEGUY, 2016). Por isso, os trabalhos analisavam o modo pelo qual os discursos dominantes da mídia reforçavam papéis tradicionais de gênero e uma visão machista da sociedade ou ainda problematizar as subordinações e desigualdades entre mulheres e homens, refutando o determinismo biológico e deslocando o peso das determinações econômicas (ESCOSTEGUY, 2016).

A partir da década de 1980, essa leitura homogeneizante foi tensionada e a diversidade entre as mulheres passou a ser considerada. Os estudos se concentraram nas

\footnotetext{
${ }^{3}$ Chamava-se Women's Studies Group em inglês. Era constituído por pesquisadoras mulheres como Angela McRobbie, Charlotte Brundson, Dorothy Robson e Janice Winship.

${ }^{4}$ Coletânea de trabalhos escritos por mulheres tratando da categoria gênero dentro das relações sociais. Antes disso, poucos artigos se preocupavam com as questões das mulheres na sociedade.
} 


\section{VOZES $_{\text {\&IÁLORO }}^{\mid}$}

Itajaí, V. 20, n.02, jun-dez 2021

diferenças entre elas, recusando a ideia de universalização e destacando aspectos como a construção da identidade de gênero e seu caráter histórico (ESCOSTEGUY, 2016). Nesse período também, conforme a autora, começou a se fazer uma crítica feminista da mídia. Na década de 1990, as pesquisas se voltaram ainda mais para o reconhecimento das diferenças entre as mulheres e houve o entendimento da categoria gênero como construção social relacionado à ideia de identidade (ESCOSTEGUY, 2016).

No Brasil, os estudos que tratam das relações de gênero se desenvolvem e acompanham os momentos do movimento feminista, considerando-se, assim, que essas investigações começaram a partir da década de 1970 (SILVA, 2000). O feminismo aparece para apontar as diferenças de gênero e abordar a ideia de resistência (MESSA, 2008). Nas décadas de 1980 e 1990, os Estudos Culturais se desenvolveram e se consolidaram, abrindo espaço para que as pesquisas feministas envolvendo mídia crescessem. Nos últimos anos, algumas jovens pesquisadoras brasileiras têm se dedicado a tematizar os entrecruzamentos entre questões de identidade, feminismo/pós-feminismo e mídia, contribuindo com o debate internacional (ESCOSTEGUY, 2016).

Com os Estudos Culturais, a concepção abrangente de cultura e o feminismo, as mulheres conseguiram mais visibilidade para as discussões sobre suas realidades e experiências. Apesar da ruptura que provocaram no trabalho do Centro de Estudos Culturais Contemporâneos, as feministas foram obrigadas a uma existência contra a corrente e à margem academicamente, sempre reforçando a importância de suas pautas e reivindicando seu espaço. Contudo, essa dificuldade fez com que elas compreendessem melhor a pluridimensionalidade do poder e da dominação, bem como a plurivalência das alianças nas práticas discursivas hegemônicas, resultando em maior entendimento das possibilidades de resistência (COSTA, 2014). Assim, os estudos feministas nesse campo têm o olhar para as práticas socais e culturais, como as da mídia, buscando evidenciar e problematizar as estruturas e as manifestações de poder e de dominação na sociedade.

\section{Epistemologias feministas: principais debates}

As Epistemologias Feministas surgem ligadas as Epistemologias do Sul. Esse termo faz referência às intervenções epistemológicas e seus conhecimentos e reflexões que buscam reparar os danos e os impactos historicamente provocados pelo capitalismo colonial na sua relação com o mundo (SANTOS; MENESES, 2009). Não se trata apenas do Sul no quesito geográfico do planeta, mas também dos indivíduos e grupos sociais que foram e são explorados e subordinados à dominação capitalista, como é o caso das mulheres. Assim, as Epistemologias do Sul valorizam a diversidade e a pluralidade epistemológica do mundo.

A partir da década de 1970, o feminismo evidencia que a maioria dos cientistas são homens, fazendo com que sua crítica se volte para essa ciência hegemônica e 


\section{VOZES $_{\text {\&IÁLORO }}^{\mid}$}

Itajaí, V. 20, n.02, jun-dez 2021

preocupando-se em construir outros modelos de ciência (CONCEIÇÃO; ARAS, 2014), como o desenvolvimento das Epistemologias Feministas. A crítica feminista identifica que o modelo dominante de fazer ciência foi construído com base em preceitos masculinos e está impregnado por valores masculinos, bem como historicamente os homens sempre tiveram mais espaço na comunidade científica.

As Epistemologias Feministas buscam investigar o papel do gênero nas atividades epistêmicas e elucidar e questionar o preconceito de gênero infiltrado nas diversas áreas do conhecimento humano (KETZER, 2017). Por vivermos em uma sociedade capitalista e patriarcal, os conhecimentos produzidos, inclusive pela ciência, tendem a reforçar a lógica da dominação capitalista e masculina e de opressão das mulheres e do feminino, suprimindo os saberes pensados e elaborados pela ótica delas.

A crítica feminista à ciência denuncia seu caráter particularista, ideológico, racista e sexista de trabalhar com um conceito universal de homem, branco, heterossexual, civilizado e do Primeiro Mundo, excluindo todos aqueles que não se encaixam nesse modelo de referência (RAGO, 1998). Por isso, as Epistemologias Feministas propõem que as categorias e os conceitos sejam revisados, transformados e ressignificados para serem mais inclusivos e poderem pensar a diferença.

As teóricas feministas compreendem que o conhecimento do mundo é socialmente construído e, no mundo em que vivemos, é determinado pelo gênero (CONCEIÇÃO; ARAS, 2014). Isso porque o gênero também é uma categoria socialmente construída através dos processos de socialização de nossa cultura que molda quem as pessoas devem ser, como devem pensar e agir. Ao estudar sobre o gênero, há a possibilidade também de pesquisas a respeito dos homens e da masculinidade, adentrando um novo solo epistêmico (RAGO, 1998) com novos conceitos e teorias que contemplem essas realidades.

Com os questionamentos levantados pelo feminismo, são formulados novos objetos de estudo, conceitos e teorias que pensam o conhecimento a partir da ótica das mulheres e vinculados às pautas feministas. $\mathrm{O}$ exercício de fazer ciência sofreu, com as Epistemologias Feministas, deslocamentos teóricos, metodológicos e práticos, influenciando na elaboração da problemática, nas teorias, nos métodos de investigação, nas observações e nas análises e interpretações dos resultados. Além disso, o uso do termo Epistemologias Feministas no plural considera a existência de uma diversidade de mulheres com diferentes realidades que precisam ser incluídas no processo de construção do conhecimento.

Mas, ainda hoje, existem argumentos que veem as Epistemologias Feministas e os conhecimentos produzidos pelas mulheres com desprezo e buscam desqualificá-lo, julgando que não podem ter também a legitimidade da ciência. As críticas são voltadas para o tipo de objeto e a atitude das pesquisadoras que são acusadas de não agirem com neutralidade, articulando a construção do conhecimento com a militância (CONCEIÇÃO; ARAS, 2014). Isso demonstra não só o preconceito contra as mulheres e os seus 


\section{VOZES $_{\text {\&IÁLORO }}^{\mid}$}

Itajaí, V. 20, n.02, jun-dez 2021

conhecimentos, mas também a força e o domínio da postura tradicional do fazer ciência no mundo contemporâneo.

Por isso, são muitas as críticas do feminismo à ciência e ao modelo dominante de fazer ciência de objetividade e de neutralidade. A crítica feminista, instrumentada por um olhar desconstrucionista de gênero, revela que a Ciência Moderna não é nem nunca foi neutra (SARDENBERG, 2001), pois seus pressupostos se baseiam em conceitos e valores patriarcais do dito ser humano neutro e universal - o homem. Também, a concepção feminista pensa na subjetividade como forma de conhecimento. As Epistemologias Feministas entendem que as mulheres, que reconhecem e aceitam os pressupostos feministas, podem praticar ciência de modo diverso em um mundo que legitime esses pressupostos, sendo conscientes da intencionalidade de suas pesquisas e dos usos que delas farão (CONCEIÇÃO; ARAS, 2014).

As práticas científicas feministas se fundamentam em um projeto político de transformação das relações de gênero, enquanto um dos fundamentos da Ciência Moderna é a necessidade de separação entre fatos e valores para assegurar a objetividade na busca das verdades científicas (SARDENBERG, 2001). Ou seja, a ciência separa os conhecimentos em verdadeiros, porque são neutros e objetivos, ou falsos, por serem parciais e subjetivos. Para as Epistemologias Feministas, os conhecimentos elaborados não são verdades puras e essenciais, mas sim possibilidades de interpretação.

\section{Articulações entre estudos culturais e epistemologias feministas}

Como vimos, os Estudos Culturais são uma corrente teórica global, mas que se adapta aos contextos específicos dos diferentes territórios para produzir suas investigações de acordo com as realidades particulares. Já as Epistemologias Feministas surgem de um Sul que é geográfico, mas também por ser pensada por um grupo social que foi e segue sendo explorado pela dominação patriarcal e capitalista - as mulheres. Por isso, a articulação entre essas duas perspectivas permite olhar para grupos marginalizados, nas suas diferentes realidades e territórios.

Nos Estudos Culturais e nas Epistemologias Feministas, observamos um esforço teórico para visibilizar, compreender e discutir os fenômenos e os temas ligados à cultura e à dominação, com pluralidade de objetos e de visões sobre o mundo e as pessoas. Ambos ressaltam a necessidade de pensar a partir das margens e dos invisibilizados. Suas reflexões contribuem para o entendimento das diferentes experiências e, ao considerar as conexões entre gênero e cultura, tratam das questões, das manifestações e das representações de homens e de mulheres, suas relações e suas interações na sociedade.

Desde o seu início, os Estudos Culturais já são utilizados para analisar a comunicação e a mídia. No campo interdisciplinar do Desenvolvimento Regional cultura, 


\section{VOZES $_{\text {\&IÁLORO }}^{\mid}$}

Itajaí, V. 20, n.02, jun-dez 2021

comunicação e desenvolvimento têm inúmeras abordagens a partir dos objetos empíricos investigados e os Estudos Culturais mostram possibilidades de pesquisas (FELIPPI, 2018). Uma das perspectivas seria para compreender e analisar a dimensão cultural do desenvolvimento do território. A cultura, enquanto produção e prática social, se relaciona com o desenvolvimento visto que as manifestações e representações culturais e simbólicas impregnam o espaço geográfico (FELIPPI; BRANDT, 2016).

Já as Epistemologias Feministas, possibilitam que consideremos as práticas e as manifestações de todos os seres humanos no espaço geográfico, pois cada um deles participa da sociedade e se relaciona com território de forma diferente. No Desenvolvimento Regional, elas podem ser empregadas para olhar as mulheres, suas práticas comunicacionais e sua participação na política, na cultura e na política nas escalas local, regional, estadual e nacional, fazendo a intersecção com questões de etnia, classe social, orientação sexual e localização geográfica.

As pesquisas com Epistemologias Feministas baseiam-se no fato de que outras epistemologias tradicionais não contemplam os efeitos de gênero sobre o conhecimento, a cultura e a sociedade como um todo. Pensar a partir dessas epistemologias em uma área, como na Comunicação e no Desenvolvimento Regional, pressupõe o reconhecimento da matriz patriarcal e da estrutura de poder enraizados na cultura e na sociedade, com o entendimento que o conhecimento não é algo desvinculado do contexto cultural e que a mulher não é apenas um objeto, mas sim alguém que produz saberes relevantes.

As questões da dimensão cultural do desenvolvimento manifestam-se de diferentes formas nos territórios, que é onde ocorre a materialização das especificidades culturais dos grupos sociais e há a identificação dos sujeitos com seus ambientes (FELIPPI; BRANDT, 2016). A própria definição do que é desenvolvimento pode variar com o tempo e com o lugar e também pela opinião de um homem ou de uma mulher, pois as especificidades dos territórios e os indivíduos que compõem os grupos e a sociedade são diferentes e têm maneiras distintas de pensar e enxergar o mundo. Por isso, os Estudos Culturais propõem uma abordagem focada no contexto específico da sociedade e as Epistemologias Feministas ressaltam a necessidade de análises pelos diferentes saberes e pontos de vista, porque as mulheres também são atores sociais e suas práticas e saberes em relação ao território e a região devem ser considerados para pensar o desenvolvimento.

No Desenvolvimento Regional, os Estudos Culturais e/ou as Epistemologias Feministas podem ser empregados em conjunto com vertentes da Geografia, como a Cultural e a Feminista, para investigar o espaço geográfico. Essa articulação possibilita compreender as manifestações culturais, os múltiplos processos e temporalidades e as apropriações e territorialidades que ocorrem nos territórios.

Os Estudos Culturais entendem que existem várias culturas com diversas práticas e manifestações culturais e as Epistemologias Feministas alertam para a generalização e universalização dos sujeitos e dos conhecimentos, pois os valores e as realidades dos grupos 


\section{VOZES $_{\& \text { DIÁLORO }}^{\mid}$}

Itajaí, V. 20, n.02, jun-dez 2021

dominantes são apenas deles e não da humanidade como um todo. No Desenvolvimento Regional, essa concepção pode contribuir com outros olhares, teorias e objetos de estudo para as pesquisas, bem como o foco em experiências e indivíduos que fazem parte de grupos marginalizados da sociedade.

Há diversos temas que podem ser objeto de estudo pela perspectiva dos Estudos Culturais e das Epistemologias Feministas. A título de exemplo, os Estudos Culturais podem ser usados em pesquisas sobre o processo migratório, a (re)construção identitária dos migrantes, as identidades territoriais ou culturais (que são também manifestações de comunicação), os movimentos de resistência ou de resiliência e as produções midiáticas das indústrias culturais sobre/para/nos territórios (FELIPPI; BRANDT, 2016). Também, podemos investigar a questão da hegemonia cultural, suas resistências e o multiculturalismo, o papel da dimensão cultural no desenvolvimento e as territorialidades construídas pelos diversos grupos sociais.

Na perspectiva das Epistemologias Feministas, podemos fazer o entrecruzamento desses e outros temas com o gênero, problematizando as diferenças entre eles. O espaço e a região não são neutros, eles são condicionados pelos corpos, mas também condicionam os corpos (BUTZKE; THEIS; NEGHERBON; BRITO, 2020). As relações de gênero são relações de poder que perpassam o espaço, os territórios e as regiões, estabelecendo normas sociais e espaciais que orientam a vida das pessoas. Há ainda como fazer a intersecção com as questões de etnia, classe social e sexualidade, incluindo as identidades LGBTQIA+ e seus pontos de vista nos estudos.

No Desenvolvimento Regional, a presença dos estudos de gênero pode conferir uma compreensão relacional de região, desvencilhando-se das noções de identidades binárias e de hierarquias de etnia e classe (BUTZKE; THEIS; NEGHERBON; BRITO, 2020). Há o entendimento que as relações de gênero impactam nas diferentes dimensões do desenvolvimento e a valorização da pluralidade e da diversidade de pessoas, de experiências e de conhecimentos dentro das regiões e dos territórios.

Os Estudos Culturais propõem uma compreensão do mundo pelas especificidades das relações e lutas culturais, ultrapassando a esfera da cultura e adentrando, por exemplo, nas relações econômicas, nas estruturas da organização social e no campo antropológico da vida cotidiana (COSTA, 2014). Assim, as análises da categoria gênero são em todos os setores, nos quais homens e mulheres apresentam saberes e visões diferentes e são representados de forma distinta.

O contexto cultural é sempre resultado de relações de poder e, para intervir nele, é preciso um mapeamento dessas relações para desarticulá-las e rearticulá-las (COSTA, 2014) dentro das regiões e dos territórios. Com o apoio dos Estudos Culturais e das Epistemologias Feministas, há a possibilidade olharmos para essas relações de poder e para as práticas sociais e comunicacionais dos sujeitos a fim de entender as dinâmicas que interferem no desenvolvimento regional. 


\section{VOZES $_{\text {\&IÁLORO }}^{\mid}$}

Itajaí, V. 20, n.02, jun-dez 2021

A cultura e os diferentes conhecimentos das sociedades foram produzidos por pessoas e grupos específicos de acordo com seus interesses e visões de mundo. Há a necessidade de abordagens que valorizem o ponto de vista de indivíduos e grupos não hegemônicos e questionem a universalidade de teorias, de metodologias, de conceitos e de estruturas (CORRÊEA, 2020), como é o caso dos Estudos Culturais, das Epistemologias Feministas e outras perspectivas descoloniais.

Para qualificar, descentralizar e descolonizar a investigação social, precisamos considerar as percepções, interpretações e teorias oriundas de grupos não hegemônicos que também constroem conhecimento (CORRÊA, 2020). O mundo humano, construído por homens e mulheres, é múltiplo, diverso e plural e, para compreendê-lo, há a necessidade de pluralizá-lo, multiplicar os olhares e perceber as diferenças, resultando em muitas possibilidades de entendimento e de interpretação. Por isso, os Estudos Culturais e as Epistemologias Feministas propõem novas maneiras de pensar e estudar os fenômenos de forma pluralizada, considerando os múltiplos processos e temporalidades que ocorrem e coexistem na sociedade, influenciando e se sobrepondo uns aos outros.

\section{Considerações finais}

Historicamente, tivemos saberes e conhecimentos de culturas e de pessoas sendo invisibilizados, ignorados e apagados, sobretudos do Sul global, por não serem considerados relevantes para o modelo hegemônico científico na busca das suas verdades neutras e objetivas. Um dos desafios é pensar as possibilidades de diálogo entre Sul e Norte global, entre as suas várias realidades históricas e vivenciais (ESCOSTEGUY, 2018), que resultem em novos relacionamentos entre as partes, com a valorização de ambos os conhecimentos produzidos.

Os Estudos Culturais e as Epistemologias Feministas se apresentam como formas de valorizar todas as práticas sociais e culturais, independente da etnia, gênero, classe social, localização geográfica, etc. Esses fatores são considerados para pensar e refletir acerca dos conhecimentos produzidos pelos diferentes indivíduos. Eles assumem que as pessoas desenvolvem diversas perspectivas sobre o mundo baseados em sua posição na sociedade como, por exemplo, as mulheres têm um ponto de vista distinto dos homens devido ao diferencial de poder entre ambos.

Um dos principais desafios para os Estudos Culturais parece ser tentar considerar o conhecimento produzidos pelos intelectuais de grupos vulneráveis (CORRÊEA, 2020), como as mulheres. Isso porque, historicamente, a ciência negou espaço a esses indivíduos e grupos. O conhecimento e a pesquisa ainda são produzidos, avaliados, revisados, editados, classificados, divulgados, publicados e bolsas de estudo concedidas ou não, na maioria das vezes, por acadêmicos homens, brancos, heterossexuais, de classe média e do Norte Global (CORRÊA, 2020). Ao trazer outras perspectivas de análise, as 


\section{VOZES $_{\text {\&IÁLORO }}^{\mid}$}

Itajaí, V. 20, n.02, jun-dez 2021

Epistemologias Feministas buscam desconstruir esse modelo científico e incluir as mulheres no processo de fazer ciência.

As Epistemologias Feministas e as mulheres abrem o campo das possibilidades interpretativas, propondo múltiplos temas de pesquisa, formulando novas problematizações, incorporando todos os sujeitos sociais e construindo novas formas de pensar e de viver (RAGO, 1998). A aplicação dessas concepções nos diversos campos do conhecimento, como a Comunicação e o Desenvolvimento Regional, pode torná-los mais inclusivos e menos excludentes ao analisar as diferentes realidades, pessoas e culturas.

Ao considerarmos que a crítica epistemológica feminista deve constituir-se em um processo tanto de desconstrução como de construção (SARDENBERG, 2001), é preciso ir além de apenas estabelecer a crítica acerca dos problemas da sociedade. Isso envolve também construir novas bases teóricas e práticas com concepções e compreensões a respeito do mundo que transformem as estruturas e as relações de poder que interferem em todas as dimensões do desenvolvimento regional.

\section{Referências}

BUTZKE, Luciana; THEIS, Ivo Marcos; NEGHERBON, Caroline Laíza; BRITO, Vivian. Desenvolvimento Regional e Gênero: Mapeamento da Formação Docente e da Produção Intelectual nos PPGs em Planejamento Urbano e Regional da Região Sul do Brasil. Revista Desenvolvimento em Questão, Ijuí, v. 18, n. 50, p. 41-54, jan./mar. 2020. ISSN 2237-6453. DOI: https://doi.org/10.21527/2237-6453.2020.50.4154. Disponível em: https://www.revistas.unijui.edu.br/index.php/desenvolvimentoemquestao/article/view/9 158. Acesso em: 08 ago. 2021.

CONCEIÇÃO, Antonio Carlos Lima da; ARAS, Lina M. Brandão de. Por uma ciência e epistemologia(s) feminista: avanços, dilemas e desafios. Cadernos de Gênero e Tecnologia, Curitiba, v. 8, n. 29 e 30, p. 10-19, jan./ jun. 2014. ISSN 2674-5704. DOI: https://doi.org/10.3895/cgt.v8n29/30.6123. Disponível em: https://periodicos.utfpr.edu.br/cgt/article/view/6123/3774. Acesso em: 27 maio 2021.

COSTA, Cláudia de Lima. Os estudos culturais na encruzilhada dos feminismos materiais e descoloniais. Estudos de Literatura Brasileira Contemporânea, Brasília, n. 44, p. 79-103, jul./dez. 2014. ISSN 2316-4018. DOI: https://doi.org/10.1590/2316-4018444. Disponível em: https://periodicos.unb.br/index.php/estudos/article/view/9985. Acesso em: 22 maio 2021.

CORREAA, Laura Guimarães. Intersectionality: A challenge for cultural studies in the 2020s. International Journal of Cultural Studies, Nova Iorque, v. 23, n. 6, p. 823-832, 2020. ISSN 1460-356X. DOI: https://doi.org/10.1177/1367877920944181. Disponível em: https:/journals.sagepub.com/doi/10.1177/1367877920944181. Acesso em: 30 maio 2021. 


\section{VOZES $_{\text {\&IÁLORO }}^{\mid}$}

Itajaí, V. 20, n.02, jun-dez 2021

CUNHA, Raquel Cantarelli Vieira da. Os conceitos de cultura e comunicação em Raymond Williams. 2010. 109 f. Dissertação (Programa de Pós-Graduação em Comunicação) - Universidade de Brasília, Brasília, 2010. Disponível em: https://repositorio.unb.br/bitstream/10482/8198/1/2010_RaquelCantarelliVieiradaCunha .pdf. Acesso em: 22 maio 2021.

ESCOSTEGUY, Ana Carolina Damboriarena. Estudos culturais feministas: a importância de afirmar uma nomeação. Líbero, São Paulo, v. 26, n. 46, p. 10-25, jul./dez. 2018. ISSN 2525-3166. Disponível em: http://seer.casperlibero.edu.br/index.php/libero/article/view/1207. Acesso em: 27 maio 2021.

ESCOSTEGUY, Ana Carolina Damboriarena. Stuart Hall e Feminismo: revisitando relações. Matrizes, São Paulo, v. 10, n. 3, p. 61-76, set./dez. 2016. ISSN 19822073. Disponível em: http://repositorio.pucrs.br/dspace/handle/10923/9664. Acesso em: 21 maio 2021.

ESCOSTEGUY, Ana Carolina Damboriarena. Cartografias dos Estudos Culturais: uma versão latino-americana. Ed. on-line. Belo Horizonte: Autêntica, 2010.

ESCOSTEGUY, Ana Carolina Damboriarena. A contribuição do olhar feminista. Intexto, Porto Alegre, v. 1, n. 3, p. 1-11, jan./jun. 1998. ISSN 1807-8583. Disponível em: https://seer.ufrgs.br/intexto/article/view/3367/3951. Acesso em: 22 maio 2021.

FELIPPI, Ângela Cristina Trevisan. Comunicação e desenvolvimento: possibilidades para uma agenda de pesquisa. In: SILVEIRA, Rogério Leandro Lima da; DEPONTI, Cidonea Machado (org.). Desenvolvimento regional: processos, políticas e transformações territoriais. São Carlos: Pedro \& João Editores, 2020. p. 215-238.

FELIPPI, Ângela Cristina Trevisan. As mediações de Jesús Martín Barbero e os estudos de Comunicação no âmbito do Desenvolvimento Regional. Intexto, Porto Alegre, n. 43, p. 135-150, set./dez. 2018. ISSN 1807-8583. DOI: https://doi.org/10.19132/18078583201843.135-150. Disponível em: https://seer.ufrgs.br/intexto/article/view/81173/48789. Acesso em: 03 out. 2021.

FELIPPI, Ângela Cristina Trevisan; BRANDT, Grazielle Betina. Aproximações entre Estudos Culturais e Desenvolvimento Regional: uma proposta teórico metodológica para estudar a Comunicação na interdisciplinaridade. Revista Brasileira de Gestão e Desenvolvimento Regional, Taubaté, v. 12, n. 4, p. 44-63, dez. 2016. ISSN 1809-239X. Disponível em: https://www.rbgdr.net/revista/index.php/rbgdr/article/view/2603/555. Acesso em: 27 maio 2021.

HALL, Stuart. Estudos Culturais: dois paradigmas. In: SOVIK, Liv (org.). Da Diáspora: identidades e mediações culturais. Tradução de Adelaine La Guardia Resende. Ana Carolina Escosteguy, Claudia Alvares, Francisco Rudiger, Sayonara Amaral. Belo Horizonte: Editora UFMG; Brasília: Representação da Unesco no Brasil, 2003a, p. 131159. 


\section{VOZES $_{\text {\&IÁLORO }}^{\mid}$}

Itajaí, V. 20, n.02, jun-dez 2021

HALL, Stuart. Estudos Culturais e seu legado teórico. In: SOVIK, Liv (org.). Da Diáspora: identidades e mediações culturais. Tradução Adelaine La Guardia Resende. Ana Carolina Escosteguy, Claudia Alvares, Francisco Rudiger, Sayonara Amaral. Belo Horizonte: Editora UFMG; Brasília: Representação da Unesco no Brasil, 2003b, p. 199218.

HALL, Stuart. A centralidade da cultura: notas sobre as revoluções culturais do nosso tempo. Revista Educação \& Realidade, Porto Alegre, v. 22, n. 2, p. 15-46, jul./dez. 1997. ISSN 0100-3143. Disponível em: https://seer.ufrgs.br/educacaoerealidade/article/view/71361/40514. Acesso em: 22 maio 2021.

KETZER, Patricia. Como pensar uma Epistemologia Feminista? Surgimento, Repercussões e problematizações. Argumentos, Fortaleza, n. 18, p. 95-106, jul./dez. 2017. ISSN 1984-4247. Disponível em: http://www.periodicos.ufc.br/argumentos/article/view/31031/71650. Acesso em: 03 jun. 2021.

MESSA, Márcia Rejane. Os estudos feministas de mídia: uma trajetória angloamericana. In: ESCOSTEGUY, Ana Carolina Damboriarena (org.). Comunicação e gênero: a aventura da pesquisa. Porto Alegre: EDIPUCRS, 2008. p. 38-60.

RAGO, Margareth. Epistemologia feminista, gênero e história. In: PEDRO, Joana M.; GROSSI, Miriam P. (org.). Masculino, Feminino, Plural. Florianópolis: Ed. Mulheres, 1998. p. 1-17.

SANTOS, Boaventura de Sousa; MENESES, Maria Paula (org.). Epistemologias do Sul. Coimbra: Edições Almedina, 2009.

SARDENBERG, Cecilia Maria Bacellar. Da Crítica Feminista à Ciência a uma Ciência Feminista?. In: ENCONTRO INTERNACIONAL DA REDE FEMINISTA NORTE E NORDESTE DE ESTUDOS E PESQUISA SOBRE MULHER E RELAÇÕES DE GÊNERO, 10., 2001, Salvador. Anais [...]. Salvador: Universidade Federal da Bahia, 2001. p. 1-35. Disponível em: https://repositorio.ufba.br/ri/bitstream/ri/6875/1/Vers\%C3\%A3o\%20FInal\%20Da\%20C r\%C3\%ADtica\%20Feminista.pdf. Acesso em: 03 jun. 2021.

SILVA, Suzana Veleda da. Os estudos de gênero no Brasil: algumas considerações. Revista Bibliográfica de Geografia y Ciencias Sociales. Universidad de Barcelona, n. 262, 15 nov. 2000. ISSN 1138-9796. Disponível em: http://repositorio.furg.br/bitstream/handle/1/1212/Os\%20estudos $\% 20 \mathrm{de} \% 20 \mathrm{~g} \% \mathrm{C} 3 \% \mathrm{AA}$ nero\%20no\%20BRasil\%20algumas\%20considera\%C3\%A7\%C3\%B5es.pdf?sequence= 1. Acesso em: 22 maio 2021.

WILLIAMS, Raymond. Culture is ordinary. In: WILLIAMS, Raymond. Resources of hope: culture, democracy, socialism. Londres: Verso, 1989. p. 3-14. 